\section{METROPOLITAN HOSPITAL SUNDAY FUND.}

A meeting of the Council of the Metropolitan Hospital Sunday Fund was held at the Mansion House on Thursday, January 10, the Lord Mayor (Sir William Treloar) presiding, for the election of committees and honorary officers for the ensuing year.

The Secretary (Sir Edmund Hay Currie) said he had received a letter from Canon Pycke resigning his position on the Council, on the ground of inability to attend meetings because of advancing age. It is usual to fill clerical vacancies by members of the same denomination, and as a Roman Catholic had resigned he submitted the name of the Rev. Monsignor Howlett, Administrator of the Cathedral at Westminster, who was recommended by Archbishop Bourne. This suggestion was adopted, and the Secretary was directed to write to the Bishop of Southwark to nominate a South London clergyman to take the place of the Rev. R. S. Hassard, resigned.

To fill lay vacancies on the Council the following gentlemen were adopted, subject to their consent: Dr. James Andrews, of Hampstead, Mr. Frank Debenham, Mr. C. E. Layton, Mr. Alexander Millar, and Mr. A. G. Phillips.

The Distribution Committee was re-elected, with $\mathrm{Mr}$. Frank Bevan, Sir Joseph Dimsdale, and Sir Frederick Treves in place of Sir Sydney Waterlow and Mr. George Herring, deceased, and Sir Felix Schuster, who had resigned owing to his appointment to the India Council.

The General Purposes Committee was also re-elected, with the addition of Lord Cheylesmore.

The Secretary then brought forward a suggestion for the appointment of a Finance Committee. The Fund, he said, had never had such a Committee, but now they had large matters to deal with, such, for instance, as Mr. Herring's estate, it was thought desirable to appoint one. He thought five would be a suitable number. This was agreed to without discussion, and the following gentlemen were appointed : Alderman Sir John Bell, Mr. J. H. Buxton, Sir William Church, Mr. John Hampton Hale, and Sir Ernest Tritton.

The hon. secretaries, Sir Richard Martin and Mr. John S. Gilliat, and the hon. auditors, Messrs. W. H. Pannell and Company, were also re-elected, and the proceedings then terminated.

\section{SOCIAL AND POOR LAW PROBLEMS.}

\section{A WISE INEBRIATE.}

A MONTH or two ago Richard Harris died in the workhouse of the Haslingden Union, after a residence there of about twelve years. At one time Harris was assistant postmaster and telegraphist at the Bacup Post Office, where his brother was postmaster. The brothers also owned the leading printing and stationery business in the town. Unfortunately Harris contracted bad habits, and became so reduced that he had to be removed to the workhouse. So far the tale is a sad but common one. The sequel, however, is better than that of most similar stories. In the workhouse it was soon found out that Harris was a capable as well as an educated man, and he was given the clerical work of the establishment to do. His ability was so great that the district auditor declared that nowhere else in his district were the books so well kept as they were by Harris at Haslingden. His friends more than once urged him to leave the workhouse and take a situation outside; but he invariably refused, on the ground that in the outer world he would be subject to the same temptations as formerly, and might return to his old habits. Only a month before his death the Guardians themselves offered to appoint him one of their officers; but this offer also he refused, because if he had accepted it he would have been compelled to live outside the workhouse, and again he feared temptation. Thus he remained to the end of his days nominally a pauper, though it is reckoned that his services saved the Guardians a salary of $£ 3$ a week. Doubtless he was wise in his choice; and he is to be respected for the discretion that made him remain in a safe though humble shelter. One would like to know, however, if the Guardians showed any special consideration for this ward of theirs who was to all intents and purposes a valuable servant. In similar cases, whero the pauper earns more than his board, lodging, and clothing, it might be well to give special privileges, such as that of having meals apart from the mass of the inmates-who are for the most part the reverse of refined-or of sleeping elsewhere than in the ordinary dormitory. This would encourage a man who was more weak than wicked, and knew his own feebleness, to stay where he was protected against himself, and where the severe treatment which is necessary with many paupers would drive him out into the world again to his own destruction.

\section{THE EPILEPTIC COLONY AT CHALFONT.}

IT is only in comparatively recent times that anything practical has been done for epileptics. These unfortunate creatures were classed with the insane, although between their attacks they were perfectly reasonable. But liable as they are to be at any time disabled by a fit, they cannot follow regular occupations under ordinary conditions, nor is every occupation suited for them. Outdoor work is the best for them, and to provide them with this the Chalfont Colony for Epileptics was founded in 1894. At first only eighteen invalids were received, but the work has grown, as its value has been realised, and the colony is now a little industrial village with a population of 200 patients. So far the place has been managed without running into debt, but there is now a need for more land to give occupation to the invalids, and when it happened that a farm of 150 acres in the neighbourhood of the colony was for sale at the price of $£ 5,500$, which is less than land in the neighbourhood usually costs, the Committee of the National Society for Employ. ment of Epileptics, which first founded the colony, and of which H.R.H. the Prince of Wales is President, thought it wise to purchase the farm, even though the purchase involved the borrowing of all but $£ 500$ of the money. Moreover, the demand for admittance to the colony is greater than can be met. At present female candidates for admittance have to wait for more than two years before they have a chance of acceptance, and nales not much less. To meet the requirements of these sufferers it is desirable that two new homes should be built, one for men and one for women, each to the 24 inmates. This would provide for adults, but to be considered, in whose there are also epileptic suitable feeding, and well-planned case the open-air life, sulony, would be invaluable in work that characterise the useful as their condition allows, bringing them up to be as useful as their conding approximately and in the more hopeful cases these there is at present no near normal health. But for these there is at present the provision. The Society then wants $£ 4,500$ to paly two new debt on the newly purchased land, 27,000 to build two ne homes for adults, and $£ 8,000$ to build two homes and may necessary school accommodation for children. This will be seem a large demand, but great also is the good that will has done by the money. The royal President of the Society heing expressed his approval of the appeal which is nowes of made, and which is signed by, among others, the Dukes of 
Devonshire and Northumberland, Adeline Duchess of Bedford, the Bishop of Oxford, Lord and Lady Rothschild, and Mr. Passmore Edwards. Subscriptions may be sent either to the Hon. Treasurer, H. N. Hamilton Hoare, Esq., or to the Secretary, G. Penn Gaskell, Esq., at the offices of the Society, Denison House, Vauxhall Bridge Road, Westminster, S.W.

\section{EDITOR'S LETTER-BOX.}

Our Correspondents are reminded that prolixity is a great bar tc publication, and that brevity of style and conciseness of statement publication, and that brevity of st
greatly facilitate early insertion.]

\section{INFLUENZA AND LOCAL IMMUNITY.}

To the Editor of THE HospitaL.

Sin,-Referring to my article on "Influenza and Local Immunity" in The Hosprtal for December 22 last, will you permit me to state publicly that I do not hold any such appointment as resident physician to the Smedley Memorial Hospital, Bath? The addition of this erroneous title to my signature may have been due to the fact that I was at one time consulting physician to the Smedley Memorial Fospital, Matlock. Yours, etc.,

Bloomfield Avenue, Bath.

Charles J. Whitby, M.D. Camb

Therapeutical Society's Meetings.-Tuesday, January 22, 1907 :-Therapeutical Society, in the Apothecaries' Hall, Blackfriars, E.C., at 4.30 P.M., the following papers will be read: Dr. R. B. Wild, "The Proper Scope of the Teaching of Materia Medica, Pharmacology, and Therapeutics in the Medical Curriculum " ; Dr. Bonnefin, "On a New Method of Rendering Creosote, and Cannabis Indica, Soluble" ; and "Short Notes on Certain Useful but Littleknown Drugs."

\section{NOTICE TO CORRESPONDENTS.}

All MSS., Letters, Books for Review, and other matters intended for the Editor should be addressed THE FDITOR, "THE HOSPITA " THE HOr the BUIIDINGs, 28 \& 29 SOUTHAMPTON STREET, STRAND, W.0.

The Bditor cannot undertake to return rejected $\mathrm{MS}_{\text {, }}$ even when accom panied by stamped directed envelope.

\section{Notice to Advertisers and 8ubscribers} All Advertisements, Orders for Oopies of THE HoSPITAL, and Business Communications should be addressed to THE MANAGER (Not to the Editor). THI Hospital, 28 \& 29 Southampton Street, Strand London, W.U.

The Oost of Sabscription, post free, is as follows :-Per week, 31d.; per quarter, 3s. 3d.; per half-year, 6s. 6d.; per annum, 13s. Foreign and Oolonial :-Per anzum, $19 \mathrm{~g}, 6 \mathrm{~d}$, payable in all

\section{Medioal and Administrative Appointments.}

THE ROYAL NATIONAL HOSPITAL FOR CONSUMPTION AND 1 DISEASES OF THE CHEST, VENTNOR, ISLE OF WIGHT.

Two ASSISTANT RESIDENT MEDICAL OFFICERS REQUIRED. Salary $£ 80$, with Board and Lodging in the Hospital.

Every Candidate must be doubly qualified, registered, and unmarried. He must have knowledge of Bacteriological methods.

Applications in candidate's own handwriting, stating his age and qualifications (with one copy of three recent testimonials), may be sent at once to the SECRETARY, 34 Craven Street, Charing Cross, London.

$T^{H E}$ URBAN DISTRICT COUNCIL OF ABERDARE.

APPOINTMENT OF MEDICAL OFFICER OF HEALTH.

The Council of the above district invite applications for the above appointment from duly qualified medical gentlemen holding the Diploma of Public Health.

Age not exceeding 40.

Welsh desirable.

Canvassing, directly or otherwise, will be an absolute disqualification, but candidates are at liberty to forward copies of their applications and testimonials to members of the Council.

The area of the district is 15,127 acres, and the estimated population about 48,000 .

The gentleman appointed will be debarred from Private Practice, and required to devote his whole time to the duties of his office,

Undertake the duties, charge, and control of the Infectious Disease and Isolation Hospital,

Perform the duties of Medical Officer of the Local Education Authority, and generally perform such other duties as the Council and Education Authority shall from time to time require.

The Salary will be $£ 500$ per annum, which will be allocated as follows, viz.:-

As Medical Officer of Health .... ... $\ldots \ldots \ldots \ldots 400$

As Medical Attendant and Superintendent of Hospital ... 40

As Medical Officer to the Education Authority … - ... $\frac{60}{0500}$

The appointment will be made on the 11th day of FEBRUART, 1907, and duties will commence on the 1st day of APRIL, 1907. YEARS, and will be subject to the approval of the Local Government Board.

Further particulars as to the duties, qualifications, and conditions of appointment may be obtained from the undersigned.

Applications, stating ace present oceupation qualications, with copies an to be delivered under seal to me, endorsed " Medical Officer Health," not later than the 23rd day of JANUARY instant.

Town Hall, Aberdare. THOS. PHILLIPS, Clerk.

\section{SEA MEN'S HOSPITAL SOCIETY.}

Consequent upon the promotion of Mr. J. G. Buckle, B.A., to be Assistant Secretary of the Seamen's Hospital Society, the office of Steward at the Dreadnought Hospital is now raciat.

The post-offers an opportunity to acquire vacant. Mano post the to antlopita higher hospital appointments. Candiosps appointments.

Candidates must be between 25 and 35 years of age. Salary $£ 80$ ising to $£ 100$ per annum, with partial Board in the hospital.

whom further particulars may be obtained.

P. MICHELLI,

Dreadnought Hospital, Greenwich. January 12th, 1907.

\section{Secretary.}

(773)

\section{THE BEST NATURAL APERIENT YATER.

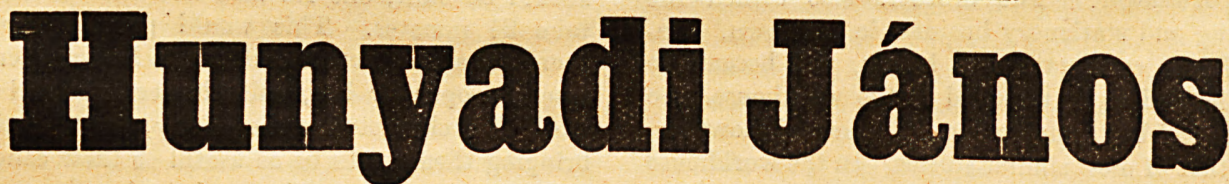

FOr LIYER COMPLAINTS, OBESITY, \&C.

The "VIENNA MEDICAL PRESS" says:-

"Hunyadi János may be regarded as a specifio for obesity.

$\Delta$ Dosic- -4 wineglassful before breakfast, either pure or diluted with a similar quantity of hot or cold wate". CAUTION

Note the name

and the Medallion, on the Red Centro Part of the Label. 